ORIGINAL ARTICLE

\title{
Etiology, presentation and treatment of ocular trauma in paediatric population.
}

\author{
Noman Ahmed ${ }^{1}$, Mehatab Alam Khanzada ${ }^{2}$, Nisar Ahmed Jandan ${ }^{3}$, Ashok Kumar Narsani ${ }^{4}$
}

Article Citation: Ahmed N, Khanzada MA, Jandan NA, Narsani AK. Etiology, presentation and treatment of ocular trauma in paediatric population. Professional Med J 2022; 29(01):67-70. https://doi.org/10.29309/TPMJ/2022.29.01.6821

\begin{abstract}
Objective: To determine the etiology, presentation and treatment of ocular trauma in paediatric population. Study Design: Cross Sectional Study. Setting: Institute of Ophthalmology, Liaquat University Hospital Jamshoro. Period: January, 2020 to December 2020. Material \& Methods: Data was collected using a questionnaire having age, sex, cause of injury and time at presentation to the emergency. It also focused on which structures were damaged due to injury, investigations being used, and treatment performed. Results: In our study we found 80 cases of ocular trauma in pediatric population visiting the ophthalmology department. Gender distribution of the study group which includes $72.5 \%(n=58)$ males and $27.5 \%(n=22)$ females. It was found during playing $86.3 \%$ of children had ocular trauma followed by injury due to domestic stuff like glass, bleach cleaners in $7.5 \%$ of the study group. The most frequently occurring ocular trauma was found to be corneal tear occurring in $25 \%$ of the study group. Conclusion: Ocular trauma in children can be prevented by simple measures like supervising children and educating parents and teachers for potential hazard substances. It is important to address like healthcare issue as ocular trauma can lead to lifelong blindness along with psychological and financial burden for the caretaker and children themselves.
\end{abstract}

Key words: Children, Etiology, Ocular Trauma.

\section{INTRODUCTION}

Eye injuries in pediatric population is a major cause of impairing vision causing significant disability, especially in pediatric and young population. Globally 18 million people have suffered uniocular vision loss due to trauma and the prevalence is disproportionately higher in children. Each year 250,000 children are found to have severe ocular trauma which could have been prevented. ${ }^{1}$ In Pakistan $45 \%$ of population is under the age of 16 years and estimated prevalence of 52,000 children are found to have visual impairment of any severity. Due to eye trauma there have been reported to have 1.6 million cases resulting in blindness and 19 million cases of monocular blindness. ${ }^{2}$ About one third cases of ocular trauma occur during the first decade of life accounting for preventable cause of unilateral blindness. ${ }^{3}$ Management of eye trauma is very crucial and if not treated early can lead to significant vision loss. Partially treated eye injuries in children can progress to amblyopia, so early management is always indicated. ${ }^{4}$ Majority of trauma can be prevented by identifying risk factors and environmental determinants, hence minimizing prevalence of ocular trauma. Trauma to the eye is the most common cause for admissions in the ophthalmology department and the estimated financial burden reaches up to hundred million dollars per year. The prevalence of eye trauma is higher in developing countries adding up to the economic crisis of the country. ${ }^{5}$ Data regarding ocular trauma in developing countries is still very limited due to less reporting of cases and absence of national database for information. Due to lack of education and healthcare services in developing countries, immediate treatment could not be provided which results in complications and vision loss. ${ }^{6}$ Factors promoting ocular injuries include lack of seat belt use, less use of safety eyewear, no adult supervision while kids playing and violence.

\footnotetext{
1. MBBS, MCPS, FCPS (Ophthalmology), Assistant Professor Ophthalmology, Liaquat University of Medical \& Health Sciences Jamshoro.

2. MBBS, FCPS (Ophthalmology), Associate Professor Ophthalmology, Liaquat University of Medical \& Health Sciences Jamshoro.

3. MBBS, MS (Ophthalmology), Assistant professor Ophthalmology, Peoples University of Medical \& Health Sciences For women Nawabshah SBA.

4. MBBS, FCPS (Ophthalmology), Professor of ophthalmology, Liaquat University of Medical \& Health Sciences Jamshoro.
}

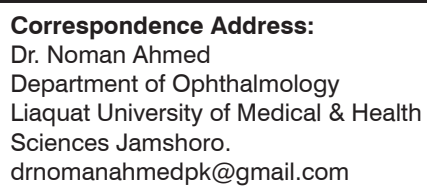

Article received on: Accepted for publication:

$24 / 09 / 2021$ $23 / 11 / 2021$ 
Hence, ocular trauma is a preventable cause of blindness worldwide. ${ }^{7}$ Majority of the studies suggested that ocular trauma was more frequently found in younger boys, whereas in children younger than 5 years injuries were found equally in girls and boys. ${ }^{8}$ Ocular trauma frequently presents as laceration or rupture both of which are challenging in pediatric population and have higher chances of complications. Surgical management if required requires expertise and compliance for post-operative follow-up. ${ }^{9}$ In our study we aim to determine the etiology, presentation and management for ocular trauma in pediatric population.

\section{MATERIAL \& METHODS}

This is a cross sectional study conducted at the Institute of Ophthalmology, LUMHS Jamshoro during the time of January, 2020 to December, 2020. The study focused on etiology, time of presentation and treatment for ocular trauma in pediatric population. During this time interval of one year, we collected cases of ocular trauma in pediatric population and collected their data. Data was collected using a questionnaire having age, sex, cause of injury and time at presentation to the emergency. It also focused on which structures were damaged due to injury, investigations being used, and treatment performed. Only the cases with complete diagnosis and treatment were included in the study. The data also included whether medical or surgical treatment was performed. Cases with incomplete treatment and leave against medical advice (LAMA) were excluded from the study. Analysis was done by SPSS version 21 and descriptive statistics were used.

\section{RESULTS}

In our study we found 80 cases of ocular trauma in pediatric population visiting the ophthalmology department. Table-I shows gender distribution of the study group which includes $72.5 \% \quad(n=58)$ males and $27.5 \%(n=22)$ females.

In our study the etiology of ocular trauma was also inquired and it is shown in Table-l. It was found during playing $86.3 \%$ of children had ocular trauma followed by injury due to domestic stuff like glass, bleach cleaners in $7.5 \%$ of the study group. Other minor causes include trauma due to occupational stuff like battery water and road traffic accidents.

In our study population $98.8 \%$ of ocular trauma occurred due to accident whereas only one case was due to assault. Majority of the children had unilateral ocular trauma whereas bilateral ocular trauma occurred in only $6.3 \%$ of the cases. The duration from occurrence of trauma to the presentation at hospital is important. In our study $75 \%$ of cases reached hospital within first 24 hours as shown in Table-I. Upon reaching the hospital $5 \%$ of patients had no perception of light whereas others had positive perception of light.

After reaching the hospital, B scan was done in 35 cases, CT scan in 2 cases and no investigation was performed in 43 cases. Table-Il shows the diagnosis of children made by ophthalmologist. The most frequently occurring ocular trauma was found to be corneal tear occurring in $25 \%$ of the study group.

Chart-2 shows the treatment given for ocular trauma in ophthalmology department. Around $52.5 \%(n=42)$ of the cases required surgical treatment to be given.

\begin{tabular}{|c|c|c|}
\hline Demographic & $\begin{array}{l}\text { Frequency } \\
\text { (N) }\end{array}$ & $\begin{array}{c}\text { Percentage } \\
\text { (\%) }\end{array}$ \\
\hline \multicolumn{3}{|l|}{ Gender } \\
\hline - Male & 58 & $72.5 \%$ \\
\hline - Female & 22 & $27.5 \%$ \\
\hline \multicolumn{3}{|c|}{ Etiology of Ocular Trauma } \\
\hline - Playing & 69 & $86.3 \%$ \\
\hline - Domestic Stuff & 6 & $7.5 \%$ \\
\hline - Occupational Stuff & 3 & $3.8 \%$ \\
\hline - $\quad$ RTA & 2 & $2.5 \%$ \\
\hline \multicolumn{3}{|c|}{ Duration From Injury To Hospital Admission } \\
\hline - 1 Day & 60 & $75 \%$ \\
\hline - 2 Day & 14 & $17.5 \%$ \\
\hline - 3 Day & 2 & $2.5 \%$ \\
\hline - 4 Day & 4 & $5 \%$ \\
\hline
\end{tabular}




\begin{tabular}{|l|c|c|}
\hline \multicolumn{1}{|c|}{ Diagnosis } & $\begin{array}{c}\text { Frequency } \\
\text { (N) }\end{array}$ & $\begin{array}{c}\text { Percentage } \\
\text { (\%) }\end{array}$ \\
\hline Chemical injury & 3 & $3.75 \%$ \\
\hline Corneal abrasion & 10 & $12.5 \%$ \\
\hline Corneal tear & 20 & $25.0 \%$ \\
\hline Corneoscleral tear & 5 & $7.5 \%$ \\
\hline Corneal tear with hyphema & 8 & $10.0 \%$ \\
\hline $\begin{array}{l}\text { Corneoscleral tear with } \\
\text { hyphema }\end{array}$ & 6 & $7.5 \%$ \\
\hline Hyphema & 4 & $5.0 \%$ \\
\hline Upper lid cut & 2 & $2.5 \%$ \\
\hline Lower lid cut & 7 & $8.75 \%$ \\
\hline Perforated eye & 2 & $3.75 \%$ \\
\hline $\begin{array}{l}\text { Subconjuctival } \\
\text { hemmorhage }\end{array}$ & 12 & $15.0 \%$ \\
\hline
\end{tabular}

Table-II. Diagnosis of ocular trauma.

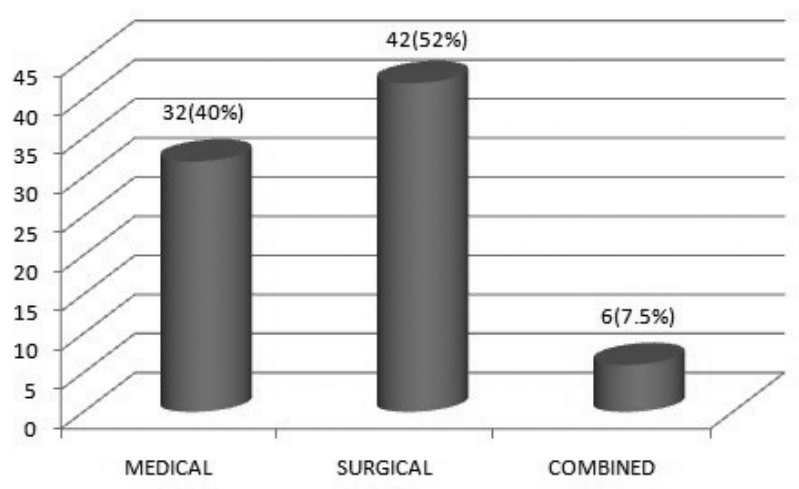

Figure-1. Treatment given for ocular trauma.

\section{DISCUSSION}

As our study describes the etiology and presentation of ocular trauma in children, it also focuses on the risk factors in our homes, playgrounds and workplace. Prevention of ocular trauma is possible so cases of blindness in children can be lowered. Pediatric population are more prone to accidental ocular trauma due to poor motor skills, curiosity and low common sense. ${ }^{9}$ As reported in our study $98.8 \%$ ocular trauma cases are accidental which could have been prevented easily.

Preventive strategies include guiding parents and children regarding potentially hazardous items and to remove it from children's reach. Adult supervision of children while playing can also lead to decrease in ocular trauma cases. Due to ocular trauma, children have to face lifetime blindness with psychological and socioeconomic impact on themselves. ${ }^{10}$ Children learn to imitate adult actions done with hazardous objects like needles and knives, cleaning household products like bleach and other cleaning liquids can also lead to eye damage.

In Pakistan child labour is common in automobile and welding workshops which also poses risk for damage to the eye. ${ }^{11}$ The prognosis in ocular trauma greatly depends upon the prompt healthcare availability and early medical/ surgical treatment. Factors delaying medical attention include socioeconomic and cultural limits leading to incurable vision loss for lifetime. As our study was carried out in Karachi approximately $75 \%$ of children received medical care within first 24 hours, delays were due to negligence of children's guardians and lack of awareness. Training of general practitioners regarding adequate medical management of eye injuries is necessary before medical attention from ophthalmologist. More than $80 \%$ of the cases in our study were open globe injuries and $25 \%$ injuries were corneal tear, while there were only $2.5 \%$ cases of perforated eye. These findings look similar to a study done on ocular trauma patterns in Egypt. ${ }^{12}$

Another finding of ocular trauma in pediatric population shows that males are affected more than females in our study as well as previous research. ${ }^{13}$ Surgical care in our study was required by $60 \%$ of the cases which suggests severe injury, whereas in another study in Pakistan showed $26.2 \%$ rate of surgical management. ${ }^{14}$ In Pakistan more than $50 \%$ of the population is below the age of fifteen and children health issues are not taken seriously. ${ }^{15}$ There is no data available for total cases of ocular trauma occurring in Pakistan, especially in the pediatric population. ${ }^{16}$ Hence studies on this topic should be carried out on large scale to evaluate etiologies and prevalence of vision loss.

\section{CONCLUSION}

Ocular trauma in children can be prevented by simple measures like supervising children and educating parents and teachers for potential 
hazard substances. It is important to address like healthcare issue as ocular trauma can lead to lifelong blindness along with psychological and financial burden for the caretaker and children themselves.

\section{Copyright@ 23 Nov, 2021.}

\section{REFERENCES}

1. Abbott J, Shah P. The epidemiology and etiology of pediatric ocular trauma. Survey of ophthalmology. 2013 Sep 1; 58(5):476-85.

2. Cariello AJ, Simerem N, Moraes B, Mitne S, Oita $\mathrm{CS}$, Fontes $\mathrm{BM}$, et al. Epidemiological findings of ocular trauma in childhood. Arq Bras Oftalmol 2007; 70(2):271-275.

3. Erwin-Mulvey LD, Nelson LB, Freeley DA. Pediatric eye trauma. Pediatr Clin North Am 1983; 30(6):1167-1183.

4. Unver Y B, Acar N, Kapran Z, Altan T. Visual predictive value of the ocular trauma score in children. $\mathrm{Br} \mathrm{J}$ Ophthalmol 2008; 92:1122-1124.

5. Saxena R, Sinha R, Purohit A, Dada T, Vajpayee RB, Azad RV. Pattern of pediatric ocular trauma in India. The Indian Journal of Pediatrics. 2002 Oct; 69(10):8637.

6. Behbehani AM, Lotfy N, Ezzdean H, Albader S, Kamel M, Abul N. Open eye injuries in the pediatric population in Kuwait. Medical Principles and Practice. 2002; 11(4):183-9.
7. Rizal SO. Epidemiology and visual outcomes of pediatric ocular trauma cases in a tertiary hospital. Philipp J Ophthalmol. 2014; 39:27-32.

8. Soliman MM, Macky TA. Pattern of ocular trauma in Egypt. Graefe's archive for clinical and experimental ophthalmology. 2008 Feb; 246(2):205-12.

9. Serrano JC, Chalela P, Arias JD. Epidemiology of childhood ocular trauma in a northeastern Colombian region. Archives of Ophthalmology. 2003 Oct 1; 121(10):1439-45.

10. McGwin G, Xie A, Owsley C. Rate of eye injury in the United States. Arch Ophthalmol2005;123:970-976

11. Arbi SD, Zaheer Mastafa MI. Etiological factors in peadiatric ocular trauma and their prevention.

12. Soliman MM, Macky TA. Pattern of ocular trauma in Egypt. Graefe's archive for clinical and experimental ophthalmology. 2008 Feb; 246(2):205-12.

13. Brophy M, Sinclair SA, Hostetler SG, Xiang H. Pediatric eye injury-related hospitalizations in the United States. Pediatrics. 2006 Jun 1; 117(6):e1263-71.

14. Noorani S, Ahmed J, Shaikh A, Shaikh ZA. Frequency of different types of paediatric ocular trauma attending a tertiary care paediatric ophthalmology department. Pakistan Journal of Medical Sciences. 2010 Jul 1; 26(3).

15. Pakistan: Population. U.S. Library of Congress. URL: http://countrystudies.us/pakistan/29.htm.

16. Lee $\mathrm{CH}$, Su WY, Lee L, Yang ML. Pediatric ocular trauma in Taiwan. Chang Gung Med J 2008; 31(1):5965.

\begin{tabular}{|c|l|l|}
\hline \multicolumn{3}{|c|}{ AUTHORSHIP AND CONTRIBUTION DECLARATION } \\
\hline No. & \multicolumn{1}{|c|}{ Author(s) Full Name } & \multicolumn{1}{|c|}{ Contribution to the paper } \\
\hline 1 & Noman Ahmed & $\begin{array}{l}\text { Conception and design, } \\
\text { Statistical expertise. }\end{array}$ \\
\hline 2 & Mehatab Alam Khanzada & $\begin{array}{l}\text { Critical revision of the article for } \\
\text { important intellectual content. } \\
\text { Critical revision of the article for } \\
\text { important intellectual content. } \\
\text { Drafting of the article. }\end{array}$ \\
\hline 3 & Nisar Ahmed Jandan & Ashok Kumar Narsani \\
\hline 4
\end{tabular}

